\title{
UMA REFLEXÃO SOBRE AS POLÍTICAS DE EDUCAÇÃO E FORMAÇÃO DOCENTE A PARTIR DA DÉCADA DE 1990 FHC A LULA.
}

\author{
Sebastião Monteiro Oliveira ${ }^{42}$ \\ Antônio Cesar Barreto Lima ${ }^{43}$ \\ Shigeaki Ueki Alves da Paixão ${ }^{44}$
}

\begin{abstract}
RESUMO
A presente pesquisa vai uma rápida incursão sobre a educação nos anos de 1990 a partir do governo de Fernando Henrique Cardoso (FHC), atendendo a agenda de órgão multilaterais. O objetivo é demonstrar o papel do governo naquele momento, destacando o modelo de competências e a Educação a Distância, chegando ao governo Lula que deu continuidade as políticas do governo anterior. A formação docente sofreu transformação para atender interesses que nunca representaram os anseios das camadas populares e nem das associações que defendem o ensino público no Brasil. A metodologia utilizada foi a pesquisa bibliográfica e documental, é um trabalho importante na medida em que faz uma reflexão sobre o atual estágio de abandono do atual governo pelo ensino público no Brasil, que corta recursos e persegue as instituições que se opõe as políticas discriminatórias e de perseguição a educadores.
\end{abstract}

Palavras - chave: Formação docente; modelo de competência; educação.

\section{A REFLECTION ON POLICIES ON EDUCATION AND TEACHING FROM THE 1990s FHC} A LULA.

\begin{abstract}
This research is going to make a quick incursion on education in the 1990s under the government of Fernando Henrique Cardoso (FHC), attending the agenda of multilateral agencies. The objective is to demonstrate the role of the government at that time, highlighting the model of competences and Distance Education, reaching the Lula government that continued the policies of the previous government. Teacher education has undergone transformation to meet interests that never represented the desires of the popular strata or of the associations that defend public education in Brazil. The methodology used was bibliographic and documentary research, it is an important work in that it reflects on the current stage of abandonment of the current government by public education in Brazil, which cuts off resources and pursues institutions that oppose discriminatory policies and persecution of educators.
\end{abstract}

Keywords: Teacher education; competence model; education.

42 Graduado em Pedagogia pela UFAM. Mestres em Educação pela UFAM, Doutor em Educação pela Universidade Nove de Julho (UNINOVE). Atualmente é Professor Associado I no CEDUC/UFRR, LOTADO no curso de Pedagogia e coordena o Grupo de Pesquisa Paulo Freire e Educação de Jovens e Adultos na Amazônia Setentrional.sabaufrr2018@gmail.com.

43 Graduado em Pedagogia pela Universidade Federal do Amazonas. Mestre em Ciências com área de Concentração em Educação Agrícola, Especialização em História Regional pela UFRR. Atualmente exerce a função de Pedagogo pelo IFRR. cesarpedago@bol.com.br

44 Doutorando do Programa Sociedade e Cultura da Amazônia - PPGSCA - ICHS UFAM.shigeak.turimo@hotmail.com. 


\section{INTRODUÇÃO}

Essa pesquisa oferece uma panorâmica sobre a educação no governo FHC chegando até o governo Lula, fazendo uma rápida reflexão sobre a formação docente e ensino a distância, bem como a influência dos órgãos multilaterais na educação brasileira e no currículo.

As políticas de formação de professores na década de 1990, têm demonstrado o caos na carreira de professor no país inteiro, considerando-se aspectos como as Diretrizes Nacionais para Formação Inicial de Professores para a Educação Básica em Nível Superior, e todas as propostas implantadas nesse período que acabaram por ser seguidas e até ampliadas pelos governos que se seguiram, portanto, será feita aqui, neste breve relato, uma exposição das políticas de formação docente, mas que por sua complexidade, não esgotará o tema, mas fica claro que uma análise mais demorada sobre a educação brasileira neste período desvaloriza o professor com o atual estágio da formação docente no início da segunda década do novo século.

Algumas velhas discussões que foram impostas, são na atualidade a ser debatidas, mas não resolvidas como deveriam, e que são tratadas nestes trabalhos, que demonstram o processo de desprofissionalização do professor e da carreira do magistério, são elas:

- A relação entre o salário docente e capacitação, até hoje não atendida, se reconhece a relação entre si, mas, na prática os professores continuam esquecidos nessa questão;

- Conhecimento do professor versus aprendizagem do aluno;

- Formação inicial e capacitação em serviço, o que não resolve a questão dos baixos salários, formação deficiente, falta de tempo para a capacitação, questões que não são resolvidas;

- Implantação da educação à distância, que já é uma realidade em todo país, dedicando uma pequena parte do trabalho a esse tema, devido a atual relevância dada a essa modalidade de ensino;

- Outras questões não menos importantes como: saber geral versus saber pedagógico, gestão administrativa versus gestão pedagógica, currículo e reforma educativa, centralização e descentralização dos modelos de formação docente.

Essas e outras questões são rapidamente tratadas neste texto, mas se apresenta como uma reflexão sobre a formação docente, dada a dimensão abrangente dessa discussão, mas a década de 90 é importante porque foi neste momento que se implantou novas propostas do governo neoliberal e também a formação docente ganhou novos contornos, com aspectos positivos e negativos. 


\section{A IMPORTÂNCIA DA LDB 9394/96 E A CRIAÇÃO DO FUNDEF: POLÍTICAS EDUCACIONAIS NA DÉCADA DE 1990}

A década de 90 é um período importante para ajudar na análise da educação no Brasil e para entender o atual estágio de oferta e de qualidade de ensino no país, nesse período começam a ser aplicados sistemas de avaliação dos sistemas de ensino, a divulgação de informações em rede de matrículas e resultados das primeiras avaliações, antes desse período era difícil fazer esse mapeamento.

No centro das políticas educacionais que foram implementadas nos anos 1990, a política de formação de professores tem sido alvo de críticas e estudos, é um período importante porque ocorreram as regulamentações e normatizações em âmbito nacional. Que norteiam hoje todo o sistema educacional e a formação docente, considerada essencial para o aprimoramento da qualidade do ensino, por todos esses motivos tem sido destacada todas as iniciativas e fatos que ocorreram nessa década, as políticas de formação docente criadas nessa década tem gerado estudos que evidenciam os fatores pessoais, institucionais e profissionais que interferem no desenvolvimento da profissão e, por conseguinte, da educação escolar. É uma questão crucial no entendimento do atual estágio em que se encontra o ensino brasileiro, particularmente a questão docente.

Também nesse período foi aprovada a LDB 9.394/96, lei que estabeleceu as diretrizes, os princípios e rumos da educação no país, que depois de uma longa e turbulenta tramitação no âmbito da Câmara Federal, foi aprovada sem nenhum veto presidencial, algo inédito na história da educação deste país.

O que torna evidente que seu conteúdo está em plena harmonia com a orientação política empreendida por Fernando Henrique sobre o setor educacional, estabelece "obrigatoriedade" e "gratuidade" ao ensino fundamental (Art. 32) e não prevê novas fontes de recursos para a educação de um modo geral. Mas que por outro lado, não representa aquilo que os educadores comprometidos com o ensino público buscavam.

Essa lei, quando se trata do financiamento da educação básica, coloca sob responsabilidade maior dos Estados e Municípios (25\% dos recursos) restando à União (18\% dos recursos) apenas uma ação "supletiva" e "redistributiva" dos recursos (Art. 74). Trata-se, portanto, de uma Lei de Diretrizes e Bases (LDB), que segundo SAVIANI (2000), é "minimalista", compatível com o "Estado mínimo" idealizado pelos neoliberais, indo de encontro aos interesses do ensino com maior responsabilidade do poder público, na contramão da proposta neoliberal. 
Para entender melhor esse período, é preciso destacar, o instrumento utilizado pelo governo FHC, que concretizou nessa década a política educacional de universalização do ensino fundamental, para isso, foram implementadas ações de financiamento para este nível de ensino exclusivamente.

Nesse período, o então Presidente da República, Fernando Henrique Cardoso, junto com o ministro da educação Paulo Renato Souza, criou o FUNDEF (instituído pela Emenda Constitucional $\mathrm{n}^{\circ} 14$ e regulamentado pela lei 9.424/96) que entre outras coisas modifica o regime de colaboração entre a União, os Estados e Municípios. Há estas duas últimas esferas administrativas e ao Distrito Federal, caberia a aplicação de $60 \%$ do percentual constitucional mínimo de $25 \%$ da receita de impostos no ensino fundamental. Seriam $15 \%$ dos seguintes impostos: ICMS (Imposto sobre a Circulação de Mercadorias e Serviços), FPE (Fundo de Participação dos Estados), FPM (Fundo de Participação dos Municípios), IPI exportação (Imposto sobre Produtos Industrializado e exportados) e a compensação financeira prevista pela lei complementar 87/96 (lei Kandir). A União caberia apenas complementar os recursos do fundo, sempre que, em cada Estado e no Distrito Federal, seu valor por aluno/ano não alcançar o mínimo definido nacionalmente. Para concretizar essa panorama com a criação do FUNDEF, o governo aprova a chamada emenda 14 :

\footnotetext{
O governo federal através da Emenda n ${ }^{\circ}$ 14, alterou o Art. 60 do Ato das Disposições Constitucionais Transitórias (ADCT) da constituição federal de 1988 , diminuindo de $50 \%$ para menos do que o equivalente a $30 \%$ do percentual da receita vinculada a educação, que deveria aplicar na erradicação do analfabetismo e na manutenção de desenvolvimento do ensino fundamental (1999: 45).
}

Para melhor entendimento das políticas de formação docente neste período, se torna importante destacar fatores negativo a respeito do FUNDEF e do descompromisso do governo FHC, salientado por ARELARO (1999) no artigo em que faz uma avaliação do primeiro ano de execução do FUNDEF, e mais recentemente ratificado por PINTO (2002) em um estudo em que avalia os dois períodos de gestão de FHC, é o não cumprimento por parte do governo Fernando Henrique Cardoso na forma de cálculo do valor mínimo a ser gasto por aluno, constante na lei 9.424/96. Com isso, calcula-se, o ensino fundamental deix ou de receber cerca de dez bilhões de reais de recursos federais desde 1998 (p.4).

O descompromisso demonstrado, com a estratégia de privatização do campo educacional via transferência de responsabilidades para a sociedade, a família e organizações não governamentais, do governo federal com a educação de um modo geral, principalmente 
com o ensino fundamental com o estabelecimento de uma política de racionalidade financeira com os gastos públicos, evidenciados através da LDB e dessa Emenda 14 e da lei do FUNDEF, também se fará refletir na elaboração e consolidação do Plano Nacional de Educação aprovado.

Para compreender o contexto da formação docente passa pela análise inicial dessas questões, a LDB aprovada, a criação do FUNDEF, a implantação dos sistemas de informação pelo INEP e a implantação dos sistemas de avaliação em todos os níveis da educação brasileira. O desaso com a formação inicial continua inalterada em todas as esferas.

- Diretrizes, projetos nesse período, o Ministério da Educação (MEC) vem desenvolvendo ações e discursos calcados no projeto político educacional delineado pelo Banco Mundial no relatório Prioridades e estratégias para a educação, de 1995. Os defensores desta política fogem do embate com as instituições educativas e escamoteiam ou descaracterizam propostas alternativas, desenvolvendo outras ações em diferentes frentes e programas como a aprovação do documento Diretrizes para formação inicial de professores da educação básica em cursos de nível superior (maio de 2001) - antecipando-se e desrespeitando o documento discutido pelas entidades educativas e que tramitava no Conselho Nacional de Educação (CNE), comportamento muito comum por parte do Governo.

- os Parâmetros Curriculares Nacionais (PCN), o Sistema de Avaliação da Educação Básica (Saeb), o Exame Nacional do Ensino Médio (Enem), o Exame Nacional de Cursos (Provão), o Telecurso 2000, o Salto para o Futuro, TV Escola, o Programa de Formação de Professores em Exercício (Proformação), esse programa de formação capacitou no Amazonas 7.000 professores do interior no curso Normal Superior, era semipresencial, foi implantando pela UEA - Universidade Estadual do Amazonas, resultado das políticas de formação dos anos 90 (PRETI, 2001).

Essas foram algumas das criações de políticas de formação ou que as influenciaram durante o Governo FHC nos anos 1990 que foram acatadas e até incrementadas pelo governo que o sucedeu, que norteia toda a organização da educação brasileira em todos os níveis de ensino. Precisaria de um trabalho mais aprofundado e longo para tratar melhor o assunto, mas esse relato permite fazer uma avaliação do compromisso e das políticas de formação docente na década de 90, principalmente dop governo tucano, que governo o país neste período.

Esse período é muito importante para compreender as atuais políticas de formação docente, foi nos anos 1990 que se iniciou a política que hoje é usada pelo Governo Dilma e foi amplamente implementada no Governo Lula, essas políticas foram adotadas pelo governo do PT e hoje, o que temos é o desdobramento dessas políticas. 
Surge como desdobramento dessa política as avaliações, as mudanças no currículo em todos os níveis da educação básica e responsabiliza o fracasso o professor e a escola nos exames padronizados que foram criados a partir desse período, criando inclusive um raqueamento de escolas com os resultados desses exames padronizados, surge então o IDEB (Índice de Desenvolvimento da Educação Básica), sem nenhum investimento na escola pública.

\section{FORMAÇÃO DE PROFESSORES SUBMETIDAS À LÓGICA DO MERCADO}

O papel da escola a partir desse momento não é mais formar o cidadão, mas especificamente formar o que o mercado determina, obedecendo a agenda e os interesses dos órgãos multilaterais como o Banco Mundial, Banco interamericanos entre outros. O governo FHC aderiu a todas as agendas desses órgãos e deu início ao modelo de educação chamado modelo de competências que hoje norteia a formação docente, $\mathrm{O}$ desmache da educação brasileira no que diz respeito a tudo que os sindicatos de professores e associações em defesa do ensino público tem lutado ao longo de décadas, incluindo nessa luta currículo, valorização de professores, investimento nas escolas e instituições de ensino superior, enfim, tudo que torne possível o ensino público gratuito, de qualidade e para todos.

A formação docente, portanto, a partir do aceite do governo FHC sofre um processo de descentralização bastante acelerado na região latino-americana. Junto ao papel tradicional dos Ministérios de Educação, abriu-se campo à colaboração da sociedade civil. Universidades, ONGs, centros de investigação, empresas privadas e empresas editoriais passaram a ter importância na oferta de capacitação de professores em serviço.

Essa situação foi à tendência predominante para as décadas seguintes, observando hoje as políticas de formação, percebemos que muitas dessas questões e influências desse período prevaleceram na forma como se elaboraram a formação docente para a Educação Básica no Brasil, e o treinamento em serviço, por exemplo, mesmo com prejuízo da qualidade e do tempo que o profissional de educação não tem, foi amplamente implementada.

Não foi sem luta que se traçou essas novas políticas de formação, os educadores comprometidos com a formação docente, em suas entidades representativas lançaram suas propostas foi o caso da ANFOPE, FORUMDIR, ANPED, ANPAE, CEDES, Fórum Nacional em Defesa da Formação de Professores, CNTE, entre outras, no sentido de identificar os (des)caminhos das políticas de formação de professores nos últimos dez anos.

O objetivo dessas associações era identificar os elementos de superação das condições atuais em que se encontrava a educação e em particular a formação de professores, campos 
assolados pelas determinações dos organismos internacionais que impõem aos diferentes países seus fins e objetivos, tornando-os subordinados às orientações políticas neoliberais e mais bem adequadas às transformações no campo da reestruturação produtiva em curso.

Porém, o que prevaleceu foram as mudanças de estratégias de formação docente, em vários dos países atualmente envolvidos em processos nacionais de reforma educativa, como a Argentina, a Bolívia, o Brasil (com destaque para o Estado de São Paulo) e o Peru. A abertura para a sociedade civil mostra, ao mesmo tempo, enormes possibilidades, mas também mostra debilidades e contradições importantes, sobretudo quando resulta em repasse, por parte do Estado, de sua responsabilidade quanto à formação docente, e quando esta fica entregue às "forças do mercado", na ausência de uma política de recursos humanos para o setor, um marco claro de orientação e renovação pedagógica e até de padrões e parâmetros de avaliação.

Essas tendências implementadas nesse primeiro momento, se tornaram realidade, visto que o Brasil adota os modelos de avaliação, pretensamente para analisar a qualidade dos sistemas de ensino em todo país, mas não trata de questões importantes como a questão das condições de trabalho, plano de carreira e do salário dos docentes, que permaneceram inalteradas e até pioraram um pouco nos últimos anos.

Não poderia deixar de mencionar aqui neste trabalho, o que foi feito no governo FHC sobre a formação de professores, que tanto mal fez para o ensino brasileiro. Seguindo a lógica da improvisação, profissionais de diferentes áreas são transformados em professores mediante uma complementação pedagógica de, no mínimo, 540 horas (LDB, art. 63, inciso I; Parecer CNE no 04/97). Desse total, 300 horas devem ser de prática de ensino (LDB, art. 65) e podem ser contabilizadas mediante capacitação em serviço (LDB, art. 61, inciso I). Ou seja, a legislação atual permite que profissionais egressos de outras áreas, em exercício no magistério, tornem-se professores valendo-se de um curso de formação docente de 240 horas! O que é inconcebível em outros campos profissionais como, por exemplo, direito, medicina e engenharia - é possível para o magistério, contrariando a própria denominação do Título VI da LDB, "Dos profissionais da educação". Mas na formação docente foi feito com o maior descaramento das autoridades da época.

Para reforçar essa política de expansão dos institutos superiores de educação e cursos normais superiores, desde 1999, obedece a balizadores postos pela política educacional em nosso país em cumprimento às lições dos organismos financiadores internacionais. Caracterizados como instituições de caráter técnico-profissionalizante, os ISEs têm como objetivo principal a formação de professores com ênfase no caráter técnico instrumental, com 
competências determinadas para solucionar problemas da prática cotidiana, em síntese, um "prático" (Freitas, 1992).

Diante dessa situação preocupante, perguntar-se-ia: A mesma urgência que justificou, na década de 1970, no Brasil, a criação dos cursos de licenciatura de curta duração está presente nas atuais proposições sobre formação docente? São os programas de formação pedagógica para portadores de diplomas de educação superior uma reedição atualizada dos desastrosos cursos de licenciatura curta? Esse esquema é uma infeliz legitimação do "bico" na profissão docente, uma vez que profissionais egressos de outras áreas, que não optaram, de início, pela carreira de magistério, provavelmente, só estão na profissão enquanto não conseguem algo melhor para fazer (PEREIRA, 99).

Foi neste contexto dos anos de 1990 que se implementou mudanças na estrutura jurídico-legal da educação brasileira, tornando manifesta a necessidade da criação de um projeto pedagógico para a formação e a profissionalização de professores nas universidades e demais instituições de Ensino Superior brasileiras. Neste período ocorrem os embates políticos sobre as concepções de educação e formação e que irão prevalecer nas décadas seguintes.

Esse novo projeto pedagógico deve estar em consonância com as modificações pretendidas na educação básica. No entanto, uma leitura mais crítica do contexto permite afirmar que, nas recentes políticas educacionais, a formação de professores corre sérios riscos de improvisação, aligeiramento e desregulamentação, o que, de certa maneira já está acontecendo, como herança do Governo FHC, amplamente seguida pelo Governo Lula.

\section{A CONSOLIDAÇÃO DAS POLÍTICAS DE FORMAÇÃO DOCENTE À DISTÂNCIA NO GOVERNO LULA DA SILVA}

Para entender o porquê da consolidação da Educação à Distância como política de formação, é importante uma rápida análise de seu surgimento. Ela é derivada da evolução do tradicional ensino presencial institucionalizado na sociedade moderna. Ao longo do desenvolvimento da História da Educação, assim como na História da Humanidade, foram superados muitos obstáculos, tanto no sistema produtivo quanto no sistema educacional. Historicamente, a educação está dividida em quatro períodos: no Mundo Antigo, no Mundo Medieval, no Mundo Moderno e no Mundo Contemporâneo (cf. Luzuriaga,1985).

A consolidação do ensino da distância começa, por parte do governo federal criando a Universidade Aberta do Brasil (UAB), por meio do Decreto ${ }^{\circ}$ 5.800/2006, durante o governo Lula, sob a responsabilidade da Diretoria de Educação a Distância, ligada à Coordenadoria de 
Aperfeiçoamento de Pessoal de Nível Superior (Capes), em parceria com a Secretaria de Educação a Distância do MEC. Seu objetivo é promover a formação inicial e continuada de professores, utilizando metodologias de educação a distância (EaD). E hoje nas universidades públicas a UAB é um núcleo para oferta de cursos nessa modalidade.

A instituição do sistema UAB ocorreu logo após a promulgação do Decreto $\mathrm{n}^{\mathrm{o}}$ $5.622 / 2005$, que conferiu novo ordenamento legal à $\mathrm{EaD}$, equiparando os cursos nessa modalidade aos cursos presenciais e estabelecendo a equivalência de diplomas e certificados na educação superior.

Essa medida legal assenta--se no pressuposto de que a EaD constitui a iniciativa de maior alcance para enfrentar as novas demandas do número de egressos do ensino médio e de formação docente, estimada, em 2002, em 875 mil vagas no ensino superior (GATTI; BARRETTO, 2009).

Então, o aparecimento e o desenvolvimento da educação a distância têm início, a partir do Mundo Contemporâneo. Para Litwin (2001), inicialmente através dos cursos por correspondência até chegar aos nossos dias, incorporando o que há de mais avançado em tecnologias da inteligência (cf. Levy, 1998). Essa modalidade não é portanto, nova, funcionava como um recurso metodológico para vencer as grandes distâncias, principalmente nos antigos cursos supletivos criados no governo militar, é o caso do Projeto Minerva, que era um programa de rádio para todo Brasil, mas esta foi apenas uma das alternativas criadas, tiveram outras.

Como tendência do avanço tecnológico, o mundo atual, resultado de inúmeras transformações na cultura, na economia, no mundo do trabalho, na política, no sistema educacional, enfim, em todos os campos do conhecimento, as rápidas mudanças tem gerado uma atualização constante, ou seja, um tipo de educação contínua ao longo da vida, que com isso tenta justificar esse número tão elevado de estudantes matriculados em cursos à distância.

A formação de professores à distância ganhou uma dimensão muito grande, essa modalidade de ensino que antes era vista como um recurso, agora, em muitas situações, se tornou um fim em si mesmo, e, portanto, acaba criando um problema, porque passa a falsa ideia de uma formação de qualidade, mas por traz está a questão de uma formação em massa com baixo custo.

A discussão sobre a formação do professor, com a lei 9394/96, ganha novos contornos, hoje, ao ser associada à modalidade de educação à distância. É importante a análise das práticas discursivas hegemônicas de mudanças na ação pedagógica, ocorridas principalmente a partir 
dos anos 90 dando (re) significação da mesma em relação à formação do professor, o gerenciamento da escola e ao uso das novas tecnologias.

Neste movimento inserem-se as propostas de formação e treinamento a distância, em expansão acelerada a partir do final da década de 90, na formação de professores, algumas "práticas" consideradas como explicativas da sua consolidação, no sentido de (res) significarmos discursos sobre a formação do professor.

O curso Mídias na Educação, oferecido pelo MEC já a algum tempo, mas principalmente na primeira década dos anos 2000, foi oferecido em larga escala em todo Brasil primeiro como curso de extensão, em módulos e depois se transformava em curso de especialização, específico para professores da rede pública, esse curso reflete a preocupação do Governo Federal para capacitar professores no sentido de saber utilizar as mídias como recurso em sala de aula, embora as escolas não reflitam a preocupação porque é necessário laboratórios de informática e com profissionais que saibam atuar nessa área e com manutenção adequada. Esse curso reflete essa tendência de cursos onlines a nível de extensão, graduação e especialização, é uma realidade nas universidades públicas e privadas.

A oferta de cursos à distância cresceu muito na última década, cerca de um terço dos futuros professores no Brasil cursa graduação a distância, segundo dados do Censo do Ensino Superior 2010, divulgado no fim do ano passado (2012). Os números mostram a importância desse tipo de ensino para a qualificação de docentes: dentre 1,3 milhão de estudantes de cursos de formação de professores, mais de 400 mil estão inscritos em instituições de Educação a Distância (EAD). Dos 230 mil que concluíram uma licenciatura há dois anos, 70 mil saíram da EAD e a formação de educadores responde por 55\% dos cursos on-line oferecidos no país.

Mas quando se fala em importância só se considera a questão da quantidade da oferta, é preciso fazer uma análise sobre a qualidade desses cursos, e a estrutura criada para seu funcionamento, quem trabalha com essa modalidade, e muitas outras questões, a EAD não pode ser um fim mas sim um meio para capacitar melhor os docentes.

Para os especialistas, a oferta desse tipo de ensino influencia na qualificação dos professores no Brasil. "Há dez anos, tínhamos um contingente muito grande de docentes que atuavam nas escolas sem formação adequada para isso, então o governo federal usou a EAD em universidades públicas como forma de incentivar esse pessoal a se graduar", esse foi o argumento de uma coordenadora de ensino de uma famosa universidade paulista para justificar o uso dessa modalidade de ensino, e é o argumento comum nos debates sobre essa questão. 
O problema da Educação à Distância, reiterando o que ficou implícito nesta parte do trabalho, é que ela acaba se tornando um fim e não um meio para facilitar as políticas de formação tanto de professores como de bacharéis, não se pode esquecer que a figura do professor não pode ser substituída pela figura de tutores, que na sua grande maioria não tem conhecimento para fazer a mediação dos conteúdos com os alunos, portanto, é preciso fazer uma análise sobre isso e considerar que o tutor não pode e nem tem condições de substituir o professor.

\section{CONSIDERAÇÕES FINAIS}

Os anos 1990 e início dos anos 2000 são muito profícuos em questão de políticas de formação docente, e a própria estrutura educacional brasileira, foi nesse período que se iniciou o sistema de avaliação e a disponibilização de dados sobre os sistemas de ensino em todo Brasil, juntando-se a isso a postura do governo com relação ao ensino público em todos os níveis, que foi de descaso, principalmente com relação ao Ensino Médio e Superior que não cabe detalhar nesse momento.

As políticas de formação docente nos anos 1990 representa a efetivação das políticas neoliberais, no que diz respeito a importância da educação enquanto instrumento impulsionador do desenvolvimento econômico do sistema capitalista, o Estado se mostrou e tem se mostrado mínimo no governo atual também.

Quando se trata do financiamento, da destinação de mais recursos para o setor educacional, tal qual a prática administrativa implementada pelo Estado Português em sua medida de "desresponsabilização" pela educação pública da colônia" (MONLEVADE, 2001, p.67). A Educvação a Distância, de certa forma, é resultado dessa preocupação, é uma política de formação mais barata e massificada.

Foi, por assim dizer, uma postura que reflete a lógica da "racionalidade financeira", recomendada por organismos internacionais de financiamento (Banco Mundial), totalmente acatada e implementada, principalmente pelo governo Fernando Henrique Cardoso, conforme evidenciado pela política educacional e de financiamento executadas durante sua gestão nos anos 90 e início dos anos 2000, seguida a risca pelo governo que o sucedeu, como bem podemos observar depois de mais de uma década do início dessas políticas.

Portanto, a década de 1990, onde se implementaram políticas neoliberais na educação pública, nos mostraram a que vieram os diferentes governantes e governos. Deixaram-nos um legado de desigualdade, concentração de renda, desemprego e miséria. O prenúncio de uma 
nova vida e uma nova humanidade somente pode ser anunciado e construído lidando com as contradições da realidade atual. Este é o desafio que está historicamente posto para os educadores e para o nosso povo, e que precisa ser desvelado nas salas de aulas, nas academias e nos encontros que tratem da defesa do ensino público.

O resultado final dessas políticas de formação docente e outras mais iniciadas na década de 1990, acabou por criar um sistema federativo de certificação de competências dos professores que determinou a desvalorização e desprofissionalização da carreira do magistério, indicando claramente que estamos vivenciando o processo de flexibilização do trabalho docente comprometendo a luta histórica dos educadores pela profissionalização e valorização do magistério desde a formação inicial até os cursos de pós-graduação, no caso, mestrado e doutorado.

É importante destacar que os governos que se seguiram, Lula e Dilma não interromperam esses compromissos assumidos por Fernando Henrique Cardoso, não sofreram descontinuidade, a EaD, que não era nenhuma inovação, pois já existia, se consolida no governo Lula e se fortalece, houveram poucas conquistas no período, como por exemplo o Piso Nacional, mas no geral a educação pública sempre esteve sobre ataque. 


\section{REFERÊNCIAS}

ARELARO, L. R. G. Financiamento e Qualidade da Educação Brasileira: algumas reflexões sobre o documento "Balanço do Primeiro ano do Fundef - Relatório MEC" IN

DOURADO, L. F. (ORG.) Financiamento da Educação Básica - Campinas, SP: Autores associados; Goiânia GO: Editora da UFG, 1999.

BRASIL. Lei no 9.394/96, de 20 de dezembro de 1996. Estabelece Diretrizes e Bases para a Educação Nacional. Disponível em:

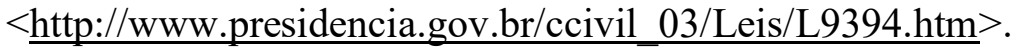

DE TOMASI, Livia; WARDE, Mirian Jorge; HADDAD, Sérgio (orgs.). O Banco Mundial e as políticas educacionais. São Paulo: Cortez, 1996.

FREITAS, Helena Costa Lopes de. Formação de professores no Brasil: 10 anos de embate entre projetos de formação. Educ. Soc., Campinas, vol. 23, n. 80, etembro/2002, p. 136-167

GATTI, Bernardet e. Formação de Professores e Carreira . Campinas : Assoc iados, 1997.

GATTI, B. A.. Análise das políticas públicas para formação continuada no Brasil, na última década. Revista Brasileira de Educação, v. 13, p. 57-70, 2008.

GATTI, B. A.. Escola: multiculturalidade e universalidade. In: SCHWARTZ, C. M. et al. (Orgs.). Desafios da educação básica: a pesquisa em educação, v. 1. Vitória: Edufes, 2007. p. $17-27$.

GATTI, B. A. Formação de professores no Brasil: características e problemas.Educação e Sociedade, Campinas, v. 31, n. 113, p. 1355-1379, out./dez. 2010.

GATTI, B. A; BARRETTO, E. S. de S. Professores do Brasil: impasses e desafios. Brasília: UNESCO, 2009. Disponível $\quad$ em: http://unesdoc. unesco.org/images/0018/001846/184682por.pdf.

GATTI, BARRETO e ANDRÉ, Bernadete Angelina, Elba Siqueira de Sá e Marli Eliza Dalmazo de Afonso. Brasília: UNESCO, 2011.

$<$ http://www.gazetadopovo.com.br/vidaecidadania/conteudo.phtml?id=1273945 https://wwws.cnpq.br/cvlattesweb/PKG MENU.menu?f cod=C343FED27BEE1FB3E6COF0747471436 9>.

LÉVY, Pierre. Cibercultura. Trad. Carlos Irineu da Costa. $2^{a}$ ed. São Paulo: Ed. 34, 2000.

. A inteligência coletiva: por uma antropologia do ciberespaço. Trad. Luiz Paulo Rouanet. 2. ed. São Paulo: Loyola, 1999.

. As tecnologias da inteligência: o futuro do pensamento na era da informática.

Trad. Carlos Irineu da Costa. Rio de Janeiro: Ed. 34, 1998.

LITWIN, Edith (org). Educação a Distância: Temas para Debate de uma Nova Agenda Educativa. Porto Alegre, Artmed, 2001.

LUZURIAGA, Lourenzo. História da Educação e Pedagogia. 16 ed., São Paulo: Nacional, 1985. (Coleção Atualidades Pedagógicas, vol. 59).

MEC/INEP. Censo do Ensino Superior. 2010. 
MONLEVADE, J. e FERREIRA, E. O FUNDEF e seus Pecados Capitais. 2 ediçãoCeilândiaDF: Idea Editora, 1998.

Idea Editora, 2001

. Educação pública no Brasil: contos e descontos. $2^{\mathrm{a}}$ edição. Ceilândia DF:

PEREIRA, Júlio Emílio Diniz. As licenciaturas e as novas políticas educacionais para a

formação docente. Revista Educação \& Sociedade, ano XX, nº 68, Dezembro/99

PINTO, J. M. R. Financiamento da Educação no Brasil: Um balanço do governo FHC (19952002). Educação e Sociedade, Setembro de 2002, Vol. 23, n ${ }^{0}$ 80), p. 108135. ISSN 01017330 .

PRETI, Oreste. Revista. Brasileira de. Estudos Pedagógicos., Brasìlia, v. 82, n. 200/201/202, p. 26-39, jan./dez. 2001.

PRETI, Oreste. Educação a distância: construindo significados. 2. ed. Brasília: Plano, 2000.

. Educação a distância e globalização: desafios e tendências. Revista Brasileira de Estudos Pedagógicos, Brasília, v. 79, n. 191, p. 19-30, jan./abr. 1998.

RHEINHEIMER, Adriana de Freitas. Política de Formação Contínua de Professores: A Descontinuidade das Ações e as Possíveis Contribuições. Formação de Professores / n.08. UNIVALI. S.d

SAVIANI, D. Da Nova LDB ao novo Plano Nacional de Educação: Por uma outra Política Educacional . $3^{\text {a }}$ edição rev. Campinas, SP: Autores Associados, 2000 (Coleção educação contemporânea).

VIEIRA, S. L. Política Educacional em Tempos de Transição (19851995). - Brasília: Plano, 2000.

. Política Educacional no Brasil: Introdução histórica. - Brasília: Plano, 2003.

WARDE, Mirian Jorge (Org). Novas Políticas Educacionais: Críticas e Perspectivas. II Seminário Internacional. Programa de Estudos Pós-Graduados em Educação. História e Filosofia da Educação. Pontifícia Universidade Católica de São Paulo. PUC. 1998. 